\title{
El teatro centroamericano del ocaso colonial. Joaquín de Oreamuno y Víctor de la Guardia'
}

\section{(Central American Theater in the Colonial Decline: Joaquín de Oreamuno and Víctor de la Guardia)}

\section{Gustavo Camacho Guzmán²}

\author{
Universidad Nacional, Costa Rica
}

\section{Resumen}

En este artículo se analizan dos textos del teatro centroamericano de principios del siglo xix: La política del mundo (1809) y tres piezas dramáticas sin título de Joaquín de Oreamuno y Muñoz de la Trinidad. Todos se escribieron para celebrar la llegada de Fernando Vii al trono español; de ahí que La política del mundo se plantee como una alegoría de las condiciones políticas del momento, en la que el traidor muere asesinado. En el aspecto ideológico, las páginas de Oreamuno y Muñoz subordinan los actos humanos al poder ultraterreno y someten a juicio al traidor de la autoridad monárquica.

\begin{abstract}
This article presents an analysis of two Central American theater texts from the early nineteenth century: the first, La politica del mundo (1809), by Víctor de la Guardia y Ayala; and the second, three untitled plays by Joaquín de Oreamuno y Muñoz de la Trinidad. All were written to celebrate the arrival of Ferdinand VII to the Spanish throne; thus, La politica del mundo is posited as an allegory of the political conditions of the period,
\end{abstract}

1 Recibido: 10 de julio de 2018; aceptado: 01 de enero de 2019.

2 Escuela de Literatura y Ciencias del Lenguaje. Correo electrónico: gustavo_a_72@hotmail.com

Letras 65 (2019), ISSN 1409-424X;EISSN 2215-4094

Doi: http://dx.doi.org/10.15359/rl.1-65.1

www.revistas.una.ac.cr/index.php/letras 
in which the traitor is murdered. Ideologically, the texts of Oreamuno and Muñoz subordinate human acts to otherworldly power and bring the traitor of the monarchical authority to trial.

Palabras clave: literatura centroamericana, teatro centroamericano, Joaquín de Oreamuno y Muñoz, Víctor de la Guardia y Ayala

Keywords: Central American literature, Central American theater, Joaquín de Oreamuno y Muñoz, Víctor de la Guardia y Ayala

Durantelaépoca colonial, CostaRica fue provincia perteneciente a la Capitanía General de Guatemala, unidad política y administrativa que en ocasiones recibía el nombre de Reino de Guatemala ${ }^{3}$. Pese a la lejanía respecto de la capital, así como de la pobreza en que vivió la población de la provincia desde el siglo xvi hasta el xix, Molina y Palmer afirman que Costa Rica exportaba una amplia cantidad de productos (tintes, materias primas, animales, entre otros), que iban destinados a los mercados de Nicaragua, Panamá, Colombia (en particular, los mercados de Cartagena) y Perú ${ }^{4}$. No obstante, tales relaciones comerciales, esos historiadores afirman que hacia 1600 Costa Rica seguía sumida en la pobreza y el aislamiento ${ }^{5}$; tal condición permitió, según Rodríguez Vega, que se formara una sociedad sin grandes diferencias de clases y con cierto sentido de autonomía en el manejo de los asuntos de gobierno, dadas las dificultades de comunicación con la capital del Reino ${ }^{6}$.

3 Hacia 1548, se instauró como unidad política en Centroamérica la llamada Audiencia de los Confines, de la cual surgiría, posteriormente, la Capitanía General de Guatemala. Véase Iván Molina y Steven Palmer, Historia de Costa Rica (San José: Editorial Universidad de Costa Rica, 2009) 20.

4 Molina y Palmer, 29-30.

5 Molina y Palmer, 27. Como ejemplo de las condiciones económicas de la provincia, Rodríguez Vega menciona la aprobación por parte de Guatemala, en 1709, para utilizar las semillas de cacao como moneda. Véase Eugenio Rodríguez Vega, Biografía de Costa Rica (San José: Editorial Costa Rica, 1980) 25.

6 Rodríguez Vega, 24 y 31. Leonardo Sancho Dobles afirma que el nombre de «Reino» se debe a que la Capitanía General dependía directamente de la Corona de España, al igual que los virreinatos. Véase Teatro breve en la provincia de Costa Rica. Tres piezas de Joaquín de Oreamuno y Muñoz de la Trinidad (Nueva York: Instituto de Estudios Auriseculares, 2016) 16. 
Durante el siglo xViii, las condiciones de vida parecen mejorar, pues se fundaron los centros que hoy cuentan con la mayor parte de la población del llamado valle central. Molina y Palmer indican que Heredia se fundó en 1706, mientras que San José se fundó en 1736 y Alajuela en $1782^{7}$. En 1766, se le concedió a Costa Rica el monopolio de la producción de tabaco, lo cual daría a la provincia una mediana prosperidad, concentrada, principalmente, en la ciudad de San José. Gracias a ello, esta ciudad pasó a ser el centro más importante de la provincia, y posteriormente, se convertiría en la capital de la nacienterepública ${ }^{8}$.

Sin embargo, aquellas condiciones económicas no serían muy favorables para el desarrollo de la cultura y de laeducación. Para Carlos Meléndez, el nivel cultural de la provincia era bajo en extremo, de ahí que los «espíritus inquietos» acabaran estableciéndose fuera de Costa Rica9. De un criterio similar es Jorge Valdeperas, quien afirma que tales circunstancias fueron la causa de que no existiera una producción teatral de importancia, dadas las condiciones de atraso y de pobreza ${ }^{10}$. Empero, durante la colonia existió una incipiente circulación de libros, por lo común, de mano en mano, que da cuenta de lo que Molina llama

7 Molina y Palmer, 39. Rodríguez Vega menciona como fecha de fundación de San José el año 1737, mientras que Stone apunta que la fundación de San José se efectuó hacia 1750, al forzar el traslado de algunos pobladores de Cartago. Sin embargo, Molina Montes de Oca afirma que no se puede establecer una fecha definitiva, en tanto el poblamiento y fundación de la capital fue un proceso gradual. Véanse Rodríguez Vega, 30; Samuel Stone, La dinastía de los conquistadores (San José: Editorial Universitaria Centroamericana, 1982) 41; y Carlos Molina Montes de Oca, Garcimuñoz, la ciudad que nunca murió (San José: Editorial de la Universidad Estatal a Distancia, 2015) 463.

8 Rodríguez Vega, 30. Pastor menciona que las reformas de Carlos iii impulsaron el comercio y el desarrollo de la sociedad centroamericana; por ejemplo, apunta que la población del área creció un $125 \%$ al final del siglo xViii, y en el caso de Costa Rica, la población se duplicó después de 1750. Véase Rodolfo Pastor, Historia mínima de Centroamérica (México: El Colegio de México, 2011) 190-195. Para un panorama de la situación centroamericana durante este periodo, véase Héctor Pérez Brignoli, Breve historia de Centroamérica (México: Fondo de Cultura Económica, 2010) 53-86.

9 Carlos Meléndez, «Algunos detalles familiares sobre Fray José Antonio de Liendo y Goicoechea», Revista de Filosofía 9 (1961): . 69-77 (69).

10 Jorge Valdeperas, Para una nueva interpretación de la literatura costarricense (San José: Editorial Costa Rica, 1991) 84-85. Este criterio es compartido por Margarita Rojas, Álvaro Quesada, Flora Ovares y Carlos Santander, al afirmar que, hacia el siglo xix, en Costa Rica, fuera de «una tradición cultural no conservada hasta hoy», la producción de artes o literatura propios no fue de importancia. Véase Margarita Rojas, Álvaro Quesada, Flora Ovares y Carlos Santander, En el tinglado de la eterna comedia. Tomo i (Heredia: Editorial de la Universidad Nacional, 1994) 15. 
un medio cultural «gris, devoto, tradicional y provinciano» ${ }^{11}$. Durante la Colonia, el libro era un bien escaso y con poco atractivo comercial, por ello, no es extraño que se lo considerara un símbolo de prestigio social, al accederse por medio de él, aun cuando el dueño no supiera leer, a una esfera culta, «asociada con el poder y la riqueza $»^{12}$. En tales circunstancias, en las que eran predominantes las páginas de carácter devoto, las posibilidades de que circularan en la provincia ejemplares recién publicados o textos de literatura de entretenimiento (novelas, comedias, otros) era exigua ${ }^{13}$.

No obstante la escasez de libros en la provincia de Costa Rica, Molina afirma que excepcionalmente aparecían algunos textosde Quevedo, de Calderón de la Barca y de La Fontaine entre las pertenencias de los comerciantes ${ }^{14}$; ello quiere decir que, a pesar de las precarias condiciones culturales, algunos habitantes de la provincia pudieron conocer literatura del Siglo de Oro español y de la Ilustración. Este panorama cambiaría después de 1814, cuando se fundó la Casa de Enseñanzade Santo Tomás(posteriormente, Universidad), en virtud de la importación de libros para abastecer la biblioteca de la institución ${ }^{15}$.

Tales circunstancias impiden generalizar sobre las condiciones culturales de la Centroamérica colonial: en la última provincia del Reino de Guatemala no solo existían libros que circulaban de mano

11 Iván Molina, El que quiera divertirse. Libros y sociedad en Costa Rica (1750-1914) (San José: Editorial de la Universidad Nacional/Editorial de la Universidad de Costa Rica, 1995) 32.

12 Molina, 21, 26.

13 Sobre las circunstancias de la actualización de libros en Costa Rica, entre los inventarios sucesorios de 1800 a 1824 en los que se citan libros y autores, aparecen mencionados textos, en su mayor parte, editados antes de 1750. Molina, 33. Al parecer, la situación cultural de Guatemala era distinta: la importación de libros era sustancial hacia 1720, hecho que permitió en los grupos criollos el contacto con las ideas de la Ilustración y un aumento en la publicación de diarios y periódicos, entre ellos, la Gaceta de Guatemala. Pastor, 178-179. Para estudiar las letras del periodo dentro y fuera del Istmo, véanse Seidy Araya, Las letras de la Ilustración y la Independencia en el Reino de Guatemala (Heredia: Editorial Universidad Nacional, 2001) y Blanca López de Mariscal, «Tráfico y circulación de libros», La escritura y el camino: discurso de viajeros en el Nuevo Mundo (México: Instituto Tecnológico y de Estudios Superiores de Monterrey) 193-208.

14 Molina, 39.

15 Un detallado análisis del catálogo bibliográfico de la Universidad de Santo Tomás aparece en Molina, 75-98. 
en mano; también se llevaron a cabo ocasionalmente, presentaciones de piezas teatrales, a pesar de las «condiciones que ofrecía el espacio y la sociedad de aquella época» ${ }^{16}$. Aun más, en los últimos años de la Colonia, Joaquín de Oreamuno y Muñoz de la Trinidad (17551827), un miembro de la sociedad cartaginesa, escribió tres piezas en verso que recuerdan a los dramas españoles del Siglo de Oro ${ }^{17}$, para representarse ante un público y con una intención ideológica clara: exaltar las virtudes del rey Fernando vii, con ocasión de su llegada al trono. Lo que es todavía más significativo es que los tres textos breves escritos por Oreamuno y Muñoz en 1809 no son únicos dentro de la producción literaria del Istmo: en ese mismo año se representó en la ciudad panameña de Penonomé ${ }^{18}$ una tragedia en tres actos y en verso: La política del mundo, de Víctor de la Guardia y Ayala, que remite al clasicismo, pues sus personajes corresponden a la tradición latina. Ambos autores cuentan con una misma intención ideológica: legitimar en las colonias la figura del monarca español, ello en una coyuntura sumamente compleja, pues pocos años después se llevarían a cabo las primeras proclamaciones de Independencia en las colonias españolas ${ }^{19}$.

16 Sancho Dobles, 51. Este autor documenta que hacia 1725 se presentó la comedia Afectos de odio y amor, de Calderón de la Barca, en casa del gobernador de la provincia, a propósito del cambio de monarca. Véase al respecto Sancho Dobles, 18.

17 En las tres piezas de Oreamuno y Muñoz, la utilización de los códigos estéticos del Siglo de Oro se combina con elementos propios de la cultura de la provincia, lo que enriquece aun más su discurso y arroja ciertas luces sobre la cultura de la Costa Rica del ocaso colonial. Véase Sancho Dobles, 159. Para un detallado estudio de la vida y participación política de Oreamuno y Muñoz, véase Jorge Francisco Sáenz Carbonell, Don Joaquín de Oreamuno y Muñoz de la Trinidad. Vida de un monárquico costarricense (San José: Editorial de la Universidad Estatal a Distancia, 1994).

18 Dentro de la administración colonial del Istmo, Panamá no pertenecía al Reino de Guatemala, sino que formaba parte, desde 1739, del virreinato de Nueva Granada, cuya capital fue Santafé (actual Bogotá). Véanse Celestino Andrés Arauz y Patricia Pizzurno. El Panamá hispano (1501-1821) (Panamá: Diario La Prensa, 1997) y Juan Sosa y Enrique Arce, Compendio de historia de Panamá (Panamá: Editorial Universitaria, 2003).

19 A pesar de los actos de legitimación de las autoridades monárquicas, desde 1809 existió un descontento, generalizado en Centroamérica, para con el régimen colonial. Esto llevó a los primeros intentos de rebelión contra las autoridades y a los primeros movimientos independentistas, entre 1810 y 1811, en las principales ciudades del Reino. Véanse Pastor, 201 y Sáenz Carbonell, 79-87. 


\section{Tres piezas de Joaquín de Oreamuno y Muñoz de la Trinidad}

El 23 de enero de 1809 se representaron en la ciudad de Cartago, cabecera de la provincia de Costa Rica, tres piezas dramáticas en ocasión de los festejos realizados por la entronización de Fernando Vii, cuyo trono había sido usurpado por Napoleón Bonaparte ${ }^{20}$.Estos textos se elaboraron con el fin de elogiar al nuevo rey de España, así como para legitimar su gobierno en las colonias. A pesar de la proverbial pobreza de Costa Rica a lo largo de la colonia, los festejos para jurar fidelidad a Fernando vii fueron vistosos: Sáenz Carbonell apunta que se organizaron misas, toques de diana, corridas de toros, bailes, espectáculos de fuegos artificiales y desfiles, efectuados entre el 14 y el 23 de enero de 1809, además de la representación en la plaza mayor de la ciudad de las piezas escritas por Oreamuno y Muñoz ${ }^{21}$.

La obra de Oreamuno consta de tres partes: una loa, un «Entremés» y una tercera pieza, de tema independiente al desarrollado en las dos anteriores. El primer texto se titula «Loa», sirve como exordio al segundo, de ahí que ambos puedan ser considerados dos partes de un mismo texto. El tercero serviría para alargar la representación, en tanto su tema está escasamente relacionado con el de los dos primeros. La loa cuenta con dos personajes (el Soldado y el Farsante) y la Música, esta última sirve a modo de coro. El Farsante, extraño venido de lejos, pregunta al Soldado por la razón del regocijo de la ciudad ${ }^{22}$; pero este, al no poder explicar el porqué de tal regocijo, deja que sea la Música quien explique: se celebra la llegada al trono de Fernando

20 Arauz y Pizzurno, 257.

21 Sáenz Carbonell, 51-59. Sancho Dobles ofrece la transcripción de los oficios y documentos oficiales relacionados con tal festejo, en ellos, se describen las diferentes actividades y celebraciones. Véanse Sancho Dobles, 161-186 y Sancho Dobles, «Siclaco, Serapio y Calandraco. Una caracterización del teatro breve en la provincia de Costarrica». Vanderbilt e-journal of LusoHispanic Studies 9 (2013): 159-169.

22 Vv. 5-48. Para citar los textos de Oreamuno, se utilizó la edición anotada de Sancho Dobles, 97-157, siguiendo la numeración de versos propuesta por este autor. Por ello, las referencias y citas de las tres piezas dramáticas consignan el número de verso y no el número de página. Otra edición de estos textos se encuentra, con ligeras variantes, en Sancho Dobles, «Unos jocosos entremeses de Joaquín de Oreamuno»: 25-80. En adelante los números de los versos se indican entre paréntesis en el texto. 
Vii y la jura de lealtad a su mandato (vv. 75-98). Ante ello, el Farsante detalla los antecedentes: Napoleón, «con arbitrios indultados/ del padre de la mentira» (vv. 126-127) usurpó el trono de España y causó grandes daños, pero Dios quiso restituir el orden y concedió el trono a su legítimo heredero, motivo por el cual se justifica el festejo que el Farsante encuentra en la ciudad (vv. 99-314). Hacia el final de la loa, es el mismo Farsante quien alude a los acontecimientos que desarrolla la segunda pieza: un juicio en contra de Napoleón «que en forma de un entremés» (v. 317), se presenta a los espectadores, por ello, pide se disculpen los errores en los que haya incurrido él en la explicación de los hechos, y da paso a la segunda parte de la representación (vv. 315-334).

Este texto introductorio cuenta con características discursivas dignas de notarse, pues el trasfondo de la exaltación al trono de Fernando vii toma tintes religiosos y moralizantes, pues son las fuerzas del bien y del mal, representadas en las figuras de Dios y del Diablo, quienes determinan las acciones de los personajes. La Música apela a los habitantes de Cartago para explicarles que, puesto que es Dios quien colocó al rey en el trono, es necesario ensalzar al soberano y agradecer el designio de la Divina Providencia; con ello, Dios premia magníficamente a las colonias de España (vv. 79-86 y 100-110). La lealtad al rey y el agradecimiento a Dios se justifican debido a que fue el Demonio quien indujo a Napoleón a usurpar el trono español, hecho que, de acuerdo con el discurso del Farsante, causó muchos males y daños a España y a sus dominios (vv. 123-140); empero, son las fuerzas del bien (Dios y Fernando vii) quienes triunfan sobre el mal (Napoleón y del Diablo). De este modo, más que un asunto terrenal, los acontecimientos obedecen a las decisiones ultraterrenas, pues los hechos políticos son, en realidad, una lucha entre Dios y el Diablo, entre el bien y el mal.

Además, es palpable la alianza entre el poder terrenal y la divinidad, no solo porque esta influye en los actos de los seres humanos, sino también porque el Farsante desea que el poder de Fernando se extienda 
a los musulmanes, al convertirse estos al cristianismo y al aceptar su poder, con lo cual este personaje, implícitamente, se califica a sí mismo como un fiel cristiano, sujeto al designio de Dios y a la autoridad del monarca. La extensión del poderío de Fernando vii recuerda las guerras entre cristianos y musulmanes, en especial, las guerras libradas en contra de la invasión en España. Por ello, resulta evidente que para los personajes, el poder terrenal está al servicio del poder divino, al ser este el brazo que extiende el cristianismo por el mundo:

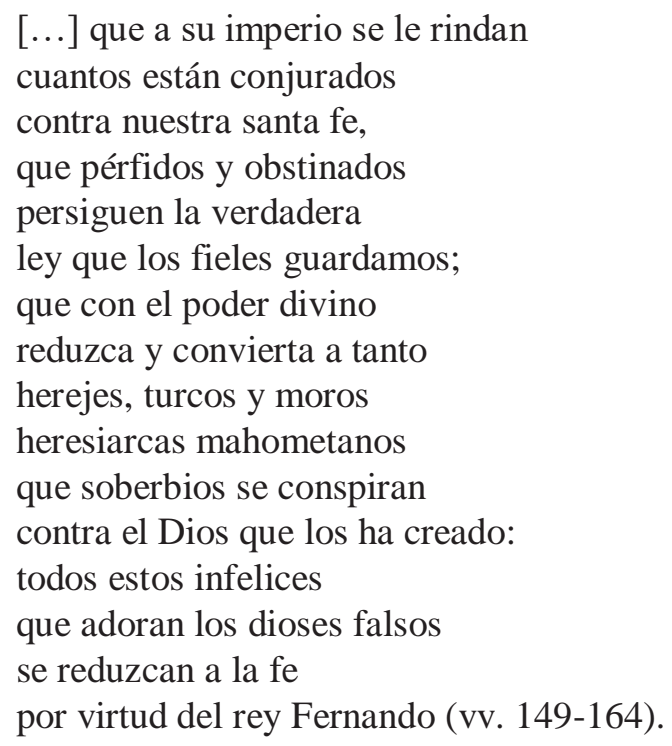

Así, el monarca no solo gobierna y decide sobre los asuntos terrenales, sino que dentro de sus funciones también se encuentra atender los asuntos ultraterrenos, a través de la expansión de la fe católica. Así, no es extraño que a Fernando vii se le considere un rey piadoso y conquistador al mismo tiempo ${ }^{23}$. Esta figura, divina y humana a la vez, se opone a la de Napoleón, por ello, en la segunda pieza, se lleva a cabo un juicio para condenarlo. Las relaciones establecidas enesta 
parte (Dios y Fernando vii frente al Diablo y Napoleón) permiten que la representación teatral tome aspectos moralizantes, pues se considera que los vicios de Napoleón lo vuelven propicio para que aniden en él los demonios. Según el Farsante, tales vicios son la codicia, la soberbia y el robo de dinero (vv. 235-246 y 283-286). De este modo, se incitaría implícitamente al auditorio a guardar cierta conducta, al presentarse el juicio y el castigo impuesto a Napoleón en la segunda pieza, como consecuencia de sus actos y de sus delitos ${ }^{24}$.

Luego del exordio, se presenta el «Entremés», pieza central del conjunto dramático escrito por Oreamuno, en tanto desarrolla el tema anunciado en la Loa. En esta parte, aparecen como personajes las virtudes cardinales (Justicia, Templanza, Prudencia y Fortaleza) quienes participan como jueces, un verdugo llamado Siclaco y el Demonio ${ }^{25}$. Esta segunda pieza empieza con una introducción de la Música, que anuncia el tema del texto: el juicio en contra de Napoleón por haber llevado a «nuestro rey» a Francia con malas intenciones (vv. 1-8) ${ }^{26}$. Acto seguido, sale la Justicia, virtud cardinal que debe presidir el juicio, para explicar un posible equívoco: aunque los personajes que van a aparecer en el entremés lleven nombres femeninos, la gravedad de las circunstancias y la severidad que debe mostrar el tribunal obligan a que sean varones quienes tomen el lugar de las virtudes. A partir de tal hecho, el autor parte de los roles tradicionales asignados al hombre y a la mujer: si la mujer es suave y misericordiosa, el hombre es vigoroso y decidido; por ello, para la Justicia es más apropiado que sean varones quienes juzguen a Napoleón, aunque el nombre de las virtudes sea femenino (vv. 9-52).

24 En la segunda parte de la representación, a Napoleón lo condenan a morir en la hoguera, para lo cual se echa mano de un muñeco de trapo con el fin de incendiarlo hacia el final de la pieza.

25 Véase Sancho Dobles, 61-62. A propósito de la clasificación de los textos como entremeses y su filiación con el teatro del Siglo de Oro, así como de la concepción respecto de estas virtu des en la teología y la filosofía, véase Sancho Dobles, 63-71.

26 El rapto de Fernando vii y su secuestro en Francia es un hecho histórico; véase al respecto Sáenz Carbonell, 51-59 y 89-98. 
Aclarado lo anterior, Siclaco se pone a las órdenes de la Justicia y le presenta los materiales con los que se dedica a ejecutar las órdenes de tal virtud: un cuchillo, la soga de la horca, una serie de látigos para azotar a los condenados y unos grillos oxidados, para que torturen con mayor eficacia a quien deba utilizarlos (vv. 53-112). La Justicia, después de alabar los instrumentos de tortura que le presentan, envía a Siclaco a buscar las virtudes para que formen parte del tribunal que ha de juzgar a Napoleón; empero, el verdugo no es un servil subalterno de la Justicia, pues este discute la decisión de llamar a la Templanza, y propone que sea la Ira quien se presente, dado que el tribunaldebe ser severo e inflexible. No obstante tal diferencia, Siclaco presenta ante la Justicia a las tres virtudes. Nuevamente, el verdugo cuestiona a su superior en cuanto al equívoco de que sean varones quienes desempeñen un papel femenino:

Señor, tan pronto me hallé

con los tres que habéis llamado,

pero sí que te reprendo

que te habéis equivocado, porque juzgué tres mujeres [...]

y me topo con tres hombres

y estos me han asegurado que se traen los tres papeles, y para mí están mojados porque le hace mucha fuerza a mi juicio temerario que los traigan tan ocultos en la bolsa y el vestuario, porque vienen tres mujeres en tres hombres disfrazados (vv. 144-161).

Las virtudes se presentan ante la Justicia y se disponen a servirle; sin embargo, la asignación del papel de cada virtud es un asunto 
arbitrario: es la Justicia quien asignó de antemano, a cada una, un rol en específico. Afirma la Prudencia:

Señor, yo soy la persona

a quien le habéis aplicado

el papel de la Prudencia [...]

Lo mismo ocurre con las otras dos virtudes: la Fortaleza y la Templanza:

Y a mí me habéis elegido, por tu gusto y por mi agrado, el papel de Fortaleza

$[\ldots]$

Por tu gusto y elección en mi habéis depositado

el papel de la Templanza, el que aprecio y he apreciado y os prometo de cumplir lo que se aplique a mi cargo (vv. 174-191).

La Justicia anuncia el propósito de la reunión: celebrar un «juicio tremendo» (v. 210) contra un traidor (Napoleón) cuyo nombre se omite. La Justicia explica los pasos por seguir: cada virtud alegará los argumentos correspondientes a cada una con el propósito de castigar razonablemente un delito, y después, se decide la sentencia que debe aplicarse al acusado (vv. 217-226). Sin embargo, en el juicio no hay derecho de defensa: de antemano la Justicia anuncia que el acusado es, desde el inicio, culpable, pues los crímenes que ha cometido superan toda proporción para imponer una pena acorde con él; de modo que las virtudes deben alegar lo que les corresponde como tales; es decir, las faltas de Napoleón en cuanto a la templanza, la prudencia y la fortaleza. Nuevamente, aparece implícito el carácter moralizante de la pieza: se juzga a Napoleón, no solo por el solo hecho de castigar sus faltas, sino también para que su castigo sirva de ejemplo para cuantos 
deseen traicionar al rey (vv. 213-215): ello lleva a la legitimación de la autoridad monárquica sobre las colonias de España en América.

La Justicia dispone el espacio para celebrar el juicio y asigna el lugar que cada virtud debe tomar. Luego, aparece Siclaco con un muñeco estafermo que representa a Napoleón. Esta introducción la acompaña una breve alocución del verdugo, en la que compara al acusado con la figura de Judas; de este modo, aparece un nuevo correlato (aparte de la relación entre ambos personajes históricos con las figuras de Dios y el Diablo): si este es Judas, Fernando vii sería Cristo. Sin embargo, la acción de Napoleón es más grave, puesto que traicionó, no solo al rey Fernando, sino también a Carlos iv y al resto del mundo (vv. 278289). Así, Siclaco no es un simple verdugo o ministro de la Justicia, sino también se toma la libertad de juzgar al acusado y señalarlo como culpable, puesto que el juicio no busca determinar la culpabilidad o inocencia del acusado, sino solamente su castigo.

La Justicia da la palabra a la Prudencia: el juicio contra el traidor no es tal, sino que se convierte en el elogio de las virtudes de Fernando Vii, con el fin de ensalzar la figura del monarca, de ahí que el acusado pase a un segundo plano, puesto que no se lo enjuicia, de antemano se encuentra juzgado ${ }^{27}$. El personaje menciona la prudencia del rey Fernando frente a los engaños y embustes de Napoleón, de ahí que sea la prudencia del rey la que haya impedido males mayores (vv. 302-341). En seguida, la Justicia da la palabra a la Fortaleza, después de emitir su propio criterio sobre el monarca, al considerar que fue gracias a la Justicia del rey que este alcanzó «el prez de ser coronado» (v. 359). Con respecto a los parlamentos de la Fortaleza y de la Templanza, ambas cuentan con una finalidad en común: elogiar la práctica de esta cualidad y demostrar que Fernando vii es ejemplo de ello:

Su fortaleza invencible

resistió a todos los bandos

que opuestos unos con otros

27 Sancho Dobles, 6. 
eran un confuso caos

de injurias, de oposiciones,

de combates infestados

por arbitrios del demonio,

unos y otros al contrario

a la defensa de Dios

y de nuestro rey Fernando.

$Y$ en fin que la fortaleza

del rey que habemos jurado

no tiene comparación

con rey ni príncipe humano (vv. 382-395).

A este aspecto se une el implícito afán moralizante para edificación de los espectadores, la Templanza afirma que esta virtud es de provecho para «todo el género humano» (v. 423), y además, es digna de practicarse en tanto sus efectos son bien vistos en la tierra y en el cielo, de ahí que el discurso del entremés dirija su atención a lo terrenal y a lo espiritual, a imitación de Fernando vii, quien tiene una labor humana y divina al mismo tiempo: gobernar España y sus colonias y extender el catolicismo por el mundo.

Quien se refiere al acusado entre los parlamentos de cada una de las virtudes es Siclaco: de los personajes, es el único que alude al acusado para injuriarlo, para calificarlo como poseso (v. 353), para compararlo con traidores tomados de la historia (como Caín, Gestas, «Judas, Caifás y Pilatos») (vv. 412-413) o para asegurar que su alma irá presa al infierno junto con sus secuaces, a semejanza de Satanás, que perdió su puesto en el cielo gracias a su rebeldía (vv. 474-504); e incluso, se sorprende de que aún el diablo no lo haya llevado consigo. A partir de este momento, las virtudes pasan a un segundo plano, pues la segunda parte de la pieza teatral se centra en una discusión, desarrollada después del juicio.

La mención al demonio es un llamado para que entre en escena un nuevo personaje: el Diablo aparece con la intención de llevarse el cuerpo de Napoleón (en la figura del estafermo) al infierno (vv. 505-538); 
Siclaco se opone a ello y entre ambos se entabla una discusión que toma tintes teológicos y morales, en la cual, el primer tema tratado es qué debe hacerse con el cuerpo de Napoleón: si ser enviado al infierno (que es lo propuesto por el Diablo) o enterrado para esperar el día del Juicio Final (como argumenta Siclaco) (vv. 557-608).

Siclaco le reprocha al Diablo el pago que da a Napoleón después de haberlo inducido a cometer maldades y daños. Esta acusación suscita la disertación del Diablo sobre el albedrío:

Aquí les pregunto yo:

¿a quién fuerzo yo al pecado?,

¿a quién precipito yo

con violencia a que sea malo?

Miente, miente quien lo dice;

quien lo piensa está engañado.

Que yo usando de mi oficio

$[\ldots]$

ponga trampas, ponga enredos, forme astucias, teja lazos,

$[\ldots]$

eso por mi gusto lo hago, pero a ninguno lo empujo que caiga precipitado:

el que cae en alguno de ellos

es por su acto voluntario (vv. 661-674) ${ }^{28}$.

Siclaco y el Diablo no consiguen ponerse de acuerdo sobre qué hacer con el cuerpo de Napoleón hasta que este, por su mano, lo prende en llamas. Ello es motivo de júbilo entre los demás personajes, que lanzan vivas a Fernando vii. Tales vivas cuentan con un fin implícito:

28 Ambos corchetes aparecen en la versión de Sancho Dobles para indicar la posible pérdida de versos, dada la rima del texto. 
convertirse en coplas para festejar el triunfo del rey y la muerte de Napoleón (vv. 715-742) ${ }^{29}$ e invitar al público a participar en tal festejo:

Todos aquestos mirones

¿por qué están tan callados?

¿Por qué no dicen a gritos

¡viva nuestro rey Fernando!?

El que no dijere a gritos

¡que viva mi rey Fernando!

sin excepción de personas

les daré de tizonazos (vv. 735-742).

La ejecución simbólica de Napoleón y la celebración del triunfo de Fernando, y por extensión, de los designios de Dios sobre las fuerzas y artimañas del Diablo, marcan el final de la representación; por ello, Siclaco barre el escenario para que desaparezcan las cenizas, y con ellas, «el contagio» del sentimiento y de las intenciones de atentar contra la autoridad del monarca (v. 760). Otra marca del final de la representación se trata delcambio de nombre de este personaje: Siclaco deja de nombrarse como tal para adoptar el nombre de Leonardo, lo que recuerda la diferencia entre personaje y actor.

Por su parte, la tercera pieza no continúa ni desarrolla los asuntos de las piezas anteriores, sino que trata otro aspecto. En esta última pieza aparecen dos personajes más: Serapio y Calandraco. Serapio abre la representación con el fin expreso de «alargar un poco» la función, para aprovechar el tablado (vv. 1-14) ${ }^{30}$. Además, se muestra complacido por la celebración de la jura del nuevo rey, pero critica a las mujeres, por medio de la elaboración de una calificación burlesca de la mujer.

Serapio critica la idea de que la mujer es de belleza perfecta, pues ello no concuerda con la realidad: la mujer cuenta con defectos que

29 Estas coplas aparecen bajo la acotación de «Bombas para el tipo que está ardiendo», al modo de la tradicional copla recitada en fiestas y celebraciones. A propósito de ello, véanse Sancho Dobles, 141 y Dionisio Cabal, ¡Bomba! La copla costarricense, (San José: D.J. Cabal A., 2012)33.

30 Véase Sancho Dobles, 62. 
la vuelven imperfecta; para ello, el personaje elabora un retrato en el que incluye las distintas partes del cuerpo y menciona que la creencia en la perfección de la mujer es un engaño del demonio (vv. 46-48). El retrato incluye los cabellos, la cara, los dientes, el pecho, la cintura y las piernas (vv. 49-107). Ante ello, aparece el último personaje de la pieza: Calandraco entra en discusión con Serapio, y le pide que, por la corona de «nuestro rey Fernando» (v. 109), se contenga de hablar mal de las mujeres. Ello implica que el rey ya cuenta con autoridad efectiva y real sobre sus súbditos, puesto que se le ha jurado lealtad, la corona aparece así como un elemento al que se le ha de tener respeto. Los dos discuten sobre si lo dicho por Serapio sobre las mujeres es un insulto, pues mientras que este lo niega, Calandraco busca desagraviar a las mujeres del auditorio (vv. 114-158). Este arguye ser fiel servidor de la mujer y elabora un elogio de la madre y la esposa, en tanto velan por sus hijos, gobiernan la despensa, alimentan a los suyos y se encargan del aseo de la casa:

¿Quién es el todo y gobierno de marido, hijos y criados?

¿Quién gobierna la despensa

y todo lo necesario

para mantener la vida

y para provechos tantos?

Que si faltan las mujeres

no hay guisado, no hay gobierno, ni en toda la casa se halla aseo, ni arreglado trasto (vv. 225-234).

Serapio responde que su única intención fue divertir al público, además de que no podría mencionar los defectos de los demás por burla, sino que su única crítica consistía en el uso de la falda corta. Esto consiste en una excusa, pues este aspecto no se había mencionado antes: 
Pues digo que es un malvado

quien murmura los defectos

que pone Dios por su mano:

solo por la nagua chinga

las conjuro de alto a abajo,

porque es el uso más feo

que pudo inventar el diablo (vv. 273-279).

Mencionada la causa del agravio, Calandraco se disculpa y ambos se reconcilian en un abrazo para lanzar las últimas vivas a Fernando vii (vv. 304-337). Las tres piezas dramáticas de Oreamuno y Muñoz de la Trinidad muestran una serie de elementos dignos de notarse, sobretodo en cuanto al aspecto social: en estos textos se legitima y ensalza el poder de las autoridades coloniales, al punto de concebirlas como garantes del orden, por ello el autor las muestra como existentes por la voluntad de Dios. A ello se suma el carácter moralizante, implícito en los textos: el castigo del traidor se trata de una acción ejemplarizante. El teatro de Oreamuno y Muñoz es de capital importancia para la tradición literaria costarricense, pues se trata de un conjunto de textos que forman parte de los orígenes del teatro nacional, al ser anteriores a la publicación de las primeras obras consagradas por la crítica como fundadoras de la dramaturgia del país ${ }^{31}$.

\section{La política del mundo, tragedia de Víctor de la Guardia}

Durante la misma época en que se representaron en Cartago las piezas de Oreamuno y Muñoz de la Trinidad, se estrenó en Penonomé (Panamá) una tragedia en verso, en tres actos. Se trata de una obra para representarse en un teatro con facilidades para llevar a las tablas un texto que demanda gran cantidad de actores y de utilería. La política

31 Sobre los orígenes del teatro nacional, véase Margarita Rojas, Álvaro Quesada, Flora Ovares y Carlos Santander, En el tinglado de la eterna comedia (Heredia: Editorial de la Universidad Nacional, 1994). Los autores mencionan como ejemplo de escritores del teatro del Olimpo a Carlos Gagini (1865-1925) y a Ricardo Fernández Guardia (1867-1950), el antecesor de tal generación fue Rafael Carranza (1840-1930). Rojas, Quesada, Ovares y Santander, 25-26. 
del mundo (1809), de Víctor de la Guardia y Ayala (1772-1827) se publicó en 1902, a instancias de Ricardo Fernández Guardia, bisnieto del autor ${ }^{32}$. A criterio de Fernández Guardia, no carece de mérito, aunque resulta en ocasiones de mal gusto, dado el «pedantismo de la época ${ }^{33}$. Según Magda Zavala, Albino Chacón y Seidy Araya, esta es la primera pieza teatral documentada escrita en Panamá ${ }^{34}$. Los autores afirman que se trata de una «pieza de circunstancias», en la cual, los personajes históricos se trastruecan, al tiempo que promueve la legitimación de la figura del monarca ${ }^{35}$. Incluso, su tono y tema responde a un predominio del gusto clasicista. No obstante estos aspectos, el texto presenta características dignas de notarse, en tanto ofrece un ejemplo de las condiciones culturales del Panamá colonial ${ }^{36}$.

El texto presenta con personajes propios de la tradición latina: César, Casio, Bruto y otros permiten caracterizar esta obra como de asunto y tono eminentemente clásico, sin embargo, el final resulta anacrónico, en tanto remite, no a una situación propia de la época a la que alude (la república y el imperio romanos), sino a un hecho contemporáneo del autor: la llegada de Fernando vii al trono de España. Por ello, las tres piezas de Oreamuno y Muñoz y el texto de Guardia y Ayala cuentan con una intención política e ideológica muy marcada, puesto que ambas desean justificar el poder español sobre las colonias, a través delteatro.

La obra empieza con un componente que también se halla en la obra de Oreamuno y Muñoz: la música, que acompaña a Calpurnia,

32 Jorge Francisco Sáenz Carbonell, El canciller Fernández Guarida (San José: Ministerio de Relaciones Exteriores y Culto de Costa Rica/Instituto del Servicio Exterior Manuel María de Peralta, 2015) 10. El texto original se hallaba en el Archivo General de Indias, de ahí que la edición de 1902 cuente al final con un colofón de Carlos Jiménez Placer, en que hace constar la fidelidad de la edición al original conservado en el Archivo.

33 Ricardo Fernández Guardia, «Al lector». La política del mundo (San José: Imprenta y Librería Española, 1902).

34 Magda Zavala, Seidy Araya y Albino Chacón. Literatura colonial de América Central. Universidad Nacional. Resultado de investigación (inédito), 55. Los autores mencionan que este autor escribió algunos textos teatrales más, de los que solo se conserva un título: La reconquista de Granada. Zavala, Chacón y Araya, 168-169.

35 Zavala, Chacón y Araya, 169.

36 Zavala, Chacón y Araya, 170. 
Porcia y Tulio. En la primera escena, los personajes plantean el tipo de conducta que debe observar quien se dedique al ejercicio del poder político, tal conducta también es propia de los dioses: la benevolencia debe ser una conducta habitual en el gobernante y en quienes ejerzan el poder y el gobierno; la Música expresa:

Ya la tiranía piadosa

dar a conocer procura

que en las deidades las iras

nunca hacen su efecto, nunca.

Por eso en los bellos brazos

de Juno, tierno se arrulla

el hermoso infante Alcides, parto de una ofensa suya, pues deponiendo los rigores, con piedad la diosa juzga

que es desaire de su esencia manifestarse iracunda ${ }^{37}$.

Para Calpurnia, quien más adelante se convierte en la esposa de Julio César, el exceso de benevolencia no es una virtud, sino que se convierte en un factor negativo, de ahí que a pesar de que en el ejercicio del gobierno se deba practicar la misericordia, es también un oficio en el que es necesario aplicarse la fuerza y la autoridad ${ }^{38}$. Ejemplo de ello es el comportamiento de Julio César y su proceder tiránico, el cual causa su posterior asesinato.

37 Víctor de la Guardia y Ayala, La política del mundo (San José: Imprenta y Librería Española, 1902) 3. La edición de 1902 no tiene numeración de versos, de ahí que, en adelante, las citas de La política del mundo consignen el número de página. Para profundizar en las figuras míticas de Juno y Alcides (correspondientes a Hera y Hércules-Heracles), véanse David Hernández de la Fuente, Mitología clásica (Madrid: Alianza Editorial, 2015) 122-129, 223-224 y Patricio de la Escosura, Manual de mitología. Compendio de la historia de los dioses, héroes y más notables acontecimientos de los tiempos fabulosos de Grecia y Roma (Madrid: Establecimiento Tipográfico de D. F. de P. Mellado, 1845) 50-55, 234-249.

38 Guardia y Ayala, 4. En adelante los números de página se indican entre paréntesis en el texto. 
Desarrollada la primera escena, Calpurnia refiere una serie de hechos que han llevado a Roma a la disensión y a la guerra civil; sin embargo, hay en el texto un rasgo que resulta interesante: ella refiere un conjunto de hechos, que según su propio discurso, pueden no ajustarse del todo a los hechos históricos, esto permite afirmar que Calpurnia es consciente del carácter literario (y por tanto, ficcional) de su propio discurso, en tanto menciona hechos que resultan ser plenamente ficcionales, no obstante la existencia de ciertas similitudes entre lo dicho por Calpurnia y la historia de Roma ${ }^{39}$ :
$[\ldots]$
estadme atentos ahora
que esta ocasión más que nunca
intento hacer un diseño
que en si la idea se apura,
concepto podrá formarse
del objeto que me impulsa,
sin que sea objeción que acaso
quien en la historia se ocupa
advierta que en una u otra
circunstancia no se ajusta
literalmente a la antigua,
porque a más de que no muda
lo substancial del relato,
se sabe que no se aúnan
los autores en los hechos
que trasladan con la pluma;
así cada cual adopta
los relatos que más gusta...(6-7)

39 Los asuntos tratados por Calpurnia son, en efecto, consignados por los historiadores de la antigüedad romana. Ella remite, en específico, a la alianza entre Pompeyo Magno, Licinio Craso y Julio César (en el 60 antes de Cristo), la disolución de esta y la consecuente guerra civil (del 49 al 45 antes de Cristo), que llevó al fin de la República y al inicio del Imperio. Véase al respecto Pedro Barceló, Breve historia de Grecia y Roma (Madrid: Alianza Editorial, 2014) 255-277. 
Calpurnia es hija de Pompeyo Magno, conquistador «del Asia, del Ponto y la Armenia» (8). En su afán de tomar el gobierno, Pompeyo se hace elegir cónsul de Roma, hecho que lo lleva a enemistarse con Licinio Craso, también elegido cónsul. Ante esta disputa, César interviene, después de haber intercedido Cicerón y Catón, y logra que se forme una alianza (9-14), reafirmada entre César y Pompeyo gracias al matrimonio de las hijas; es decir: Pompeyo se casa con la hija de Cesar, mientras que este toma a la hija de Pompeyo por esposa (15). El resultado de la alianza entre Pompeyo, Craso y César no es duradero, en tanto estos se dividen el gobierno de las provincias romanas: Pompeyo se encarga de gobernar en España, César se encarga de la Galia (Francia) y Craso se dedica a la conquista de los partos, en la cual muere junto con su hijo ${ }^{41}$. Al morir uno de los aliados, Pompeyo y César disputan el poder, lo cual desencadena una guerra civil (esta inicia con el célebre paso de Julio César por el Rubicón), en la cual es decisiva la batalla de Farsalia: César gana y Pompeyo huye a Egipto ${ }^{42}$. El poder de César se afianza con el asesinato de su antiguo contrincante.

Las circunstancias posteriores a la guerra civil colocan a César en una posición peligrosa, lo cual exige de él una conducta de carácter diplomático: Pompeyo muere a manos de Tolomeo, rey de Alejandría y hermano de Cleopatra. Ella busca a César para reivindicar sus derechos hereditarios, usurpados por su hermano, y a modo de trofeo, lleva a Julio César la cabeza de Pompeyo ${ }^{43}$. De este modo, Cleopatra solicita que él conspire en contra del hombre con quien debe estar agradecido por matar a su enemigo: las circunstancias suscitan en este personaje una reflexión sobre las condiciones en que se desarrolla la política y las relaciones, marcadas por la adulación y el engaño, entre quienes ostentan el poder político y quienes, por diversas razones, buscan tomar el poder o aprovecharse de él:

41 Guardia y Ayala, 16-18.

42 Guardia y Ayala, 20-21. César cruza el Rubicón en el 49 antes de Cristo. Barceló, 262-263.

43 Guardia y Ayala, 25-27. 
Aunque muchos me aborrecen

hoy me ven entronizado;

por eso contemporizan

conmigo, disimulando

sus anteriores rencores

con obsequios afectados.

Ayer no más me ofendían

los que ahora son mis aliados

$[\ldots]$

¡Oh política del mundo,

cuánto pueden tus engaños! (28)

El segundo acto de la tragedia comienza con la representación de la batalla de Munda, en la que César gana; cuenta con tres segmentos, cada uno de los cuales trata un tema distinto. En orden respectivo, se representa la batalla de Munda, la llegada de cartas para Calpurnia con noticias de César y la presentación de la conjura en contra del tirano. Las noticias que llegan a Roma sobre él son especialmente buenas: vence en dos emboscadas (una de ellas preparada por Casio, uno de sus generales); además, vence a Tolomeo e impone a Cleopatra como reina de Egipto (45-47, 53). Estas noticias se conocen gracias a que el vencedor regresa a Roma acompañado por Cleopatra, que se convierte en su amante (53). En la segunda mitad de este acto, el personaje que toma protagonismo es Bruto, quien está en contra del despotismo de César y conspira veladamente, de ahí que pregunte en secreto por el ánimo de Calpurnia. En esta parte aparecen otras dos conductas usuales en la política: el disimulo y el oportunismo. Scévola y Bruto comentan:

Scév. $\quad[\ldots]$ Si vieras

lo que [Calpurnia] se estira y se adorna,

lo que presume y afecta,

lo que ostenta y lo que hace,

no pensarías que era ella 
por quien me preguntas, no.

Bruto. Sí, con política diestra

en iguales circunstancias

los sentimientos se afectan.

Scév. Yo solo sé que es preciso

el que yo ahora coma y beba, que no hay política como sacar la barriga llena.

Bruto. ¡Oh ambición humana, cuántas astucias en ti se encierran! (50).

En ese momento de la representación, César adopta una actitud tiránica contra él conspiran algunos de sus colaboradores, es decir, en el ejercicio de la política se tiende a la traición y al crimen. Los acontecimientos del segundo acto perfilan el desarrollo de las acciones del tercer acto: glorioso, César regresa a Roma para recibir el homenaje a su valor, aunque tal homenaje sea frío y tenso, en tanto su poder y autoridad no resultan gratos a ciertos grupos. Cicerón refiere los festejos ordenados por el Senado en honor de César; de estos, el más significativo es la entrada en el carro triunfal, puesto que este acontecimiento permite observar las reglas de comportamiento que exige la condición de quienes son parte de la política o cercanos a ella.

Sobre este aspecto, los allegados al poderoso son quienes, en razón de su cercanía con el poder, siguen una conducta dictada según las reglas de la política: Porcia, Cleopatra y Calpurnia observan la entrada del carro triunfal, y las dos primeras, son las que adoptan una conducta que la situación les exige; Porcia exclama:

La política me exige

que celebre lo que lloro (67).

Mientras que en la misma escena, Cleopatra justifica sus elogios a César de la siguiente manera: 
Por la política es bien

que me explique de este modo (67)

El comportamiento, las palabras y las acciones de los personajes cercanos al poder político se ajustan a ciertas normas. Tal es la política del mundo: una forma de conducta, ajustada a las reglas, convenciones y maneras propias de quienes ejercen el poder o se hallan relacionados con él de algún modo, por encima de las afinidades y preferencias privadas. En tal política priman el elogio, el disimulo y la adulación a un poder que no necesariamente se ve con simpatía. Por esta última razón, la política está también teñida por la traición y el crimen: Bruto lidera la conjura en contra del general vencedor, y con la complicidad del Senado (91), asesina a César y reivindica la condición de libertad del pueblo romano. Así, resulta claro el simbolismo que Víctor de la Guardia concede a los personajes, en función de las circunstancias políticas de España al inicio del siglo xix: mientras Napoleón se corresponde con la figura de Julio César, al ser el tirano que resulta derrotado, Fernando vii, y por extensión, el pueblo español, hallarían su correspondiente en el pueblo romano, al cual Bruto libera con su acto. Esto último explicaría el anacrónico final, en que Cicerón ensalza a Fernando vii (93) y legitima su poder sobre las colonias.

\section{Conclusión}

Al igual que las piezas dramáticas de Oreamuno y Muñoz de la Trinidad, La política del mundo encierra una clara intención ideológica: legitimar del poder español en las colonias americanas. Tales actos se efectúan en medio de una coyuntura social marcada por el descontento con respecto a este poder, pues poco tiempo después brotaron los movimientos de independentismo en Centroamérica. Tal circunstancia obedece a un ambiente de libertad que se gestaba en el resto de Hispanoamérica: 
Las piezas dramáticas analizadas dan cuenta de las diferencias en cuanto a las condiciones culturales de dos colonias del Istmo: en Costa Rica se improvisó un tablado en la plaza de Cartago para presentar unos «jocosos entremeses» con ocasión de la llegada de Fernando vii al trono de Español, mientras que el texto de La política del mundo se halla, por sus propias características, diseñado para representarse en un teatro con grandes facilidades de utilería ${ }^{44} \mathrm{y}$ en condiciones de llevar a las tablas una obra con gran cantidad de personajes.

No obstante estas diferencias, la ideología subyacente en ambos textos es idéntica, se trata de homenajes al poder monárquico, en contextos delicados, dada la coyuntura social: los primeros movimientos de independencia en el continente se llevaron a cabo al año siguiente del estreno de ambos textos. A ello se suma un aspecto común: el carácter pedagógico; tanto las piezas dramáticas de Oreamuno y Muñoz de la Trinidad como la obra de Guardia y Ayala buscan promover la sujeción de las colonias al poder monárquico y presentar el castigo a la traición. Ello hace de ambos textos un ejemplo sumamente notable de las manifestaciones literarias del Istmo durante una época marcada por la historiografía tradicional como de suma pobreza cultural.

Ambas obras dan cuenta de una parte de los orígenes de la literatura criolla del Istmo; es decir, de la producción literaria de América Central a las puertas de la emancipación política con respecto aEspaña y de las condiciones culturales en que esta producción literaria tiene lugar: se trata de cantos al poder colonial (de ahí que se le pueda llamar «teatro de circunstancias») justo antes de que en el resto del continente aparecieran los movimientos de rebeldía, que a la postre, darían origen a las repúblicas de Hispanoamérica.

44 Para mencionar dos ejemplos, la escenografía implica la representación de las habitaciones de Calpurnia, el campo de la batalla de Munda y el Senado romano, con una estatua de Pompeyo. Véase Guardia y Ayala, 3, 29-37 y 89. 
